\title{
HMGB1, S100 proteins and other RAGE ligands in cancer - markers, mediators and putative therapeutic targets
}

\author{
Petra Tesarovaa ${ }^{a}$, Marta Kalousova ${ }^{b}$, Tomas Zima ${ }^{b}$, Vladimir Tesar ${ }^{c}$
}

\begin{abstract}
Background and Aims. Activation of RAGE due to its increased expression in cancer cells or its stimulation by multiple ligands (AGEs, HMGB1, S100 proteins, etc.) may contribute to the proliferation, invasiveness of tumor cells and formation of distant metastases and also to the resistance of cancer to treatment. RAGE ligands could thus become both useful markers of disease severity and its outcome and, a potential therapeutic target.

Conclusions. Better understanding of the role of RAGE activation in different types of cancer may help to define the role of ligand/RAGE antagonists as promising cancer treatment.
\end{abstract}

Key words: RAGE, HMGB1, S100 proteins, advanced glycation end products, cancer, metastasis

Received: August 29, 2015; Accepted with revision: January 22, 2016; Available online: February 3, 2016

http://dx.doi.org/10.5507/bp.2016.003

${ }^{a}$ Department of Oncology, $1^{\text {st }}$ Faculty of Medicine, Charles University and General University Hospital, Prague, Czech Republic ' Institute of Medical Biochemistry and Laboratory Diagnostics, $1^{\text {st }}$ Faculty of Medicine, Charles University and General University Hospital, Prague, Czech Republic

'Department of Nephrology, $1^{\text {st }}$ Faculty of Medicine, Charles University and General University Hospital, Prague, Czech Republic Corresponding author: Petra Tesarova, e-mail: tesarova.petra@seznam.cz

\section{INTRODUCTION}

Mechanisms of innate immunity mediate reactions to exogenous pathogens. They can also mediate the response to dying or modified cells and may play an important role in the pathogenesis of cancer. Damaged necrotic cells release different damage-associated molecular patterns (DAMPs, alarmins) which are then recognized by different pattern-recognition receptors (PRRs), activate innate immunity and induce subsequent inflammation ${ }^{1}$.

The prototypic DAMP is the high mobility group box 1 (HMGB1), a DNA-binding nuclear protein released from the cells either passively during cell death, or actively on cytokine stimulation and activating PRRs (namely TLRs and RAGE). HMGB1 may associate with Toll-like receptor (TLR) ligands and activate cells through either TLR2 and TLR4, or the multiligand receptor called RAGE (receptor for advanced glycation end-products). Whereas TLRs are more often involved in detecting PAMPs (pathogen associated molecular patterns), they are also involved in recognizing endogenous molecules associated with tissue damage ${ }^{2}$. Some ligands (e.g. HMGB1, S100A8/A9 and LPS) and signaling pathways may be shared by TLRs and RAGE and they may also cooperate in the innate immune response $\mathrm{e}^{3,4}$.

RAGE is a single-transmembrane, multiligand receptor, a member of the immunoglobulin superfamily and the gene for RAGE is located in the Class III region of the major histocompatibility complex ${ }^{5,6}$. Apart from membrane-bound RAGE, there is also a soluble RAGE which may partly function as its natural antagonist ${ }^{7,8}$. RAGE is constitutively expressed only in the lungs, but its activation may be involved in tissue homeostasis, resolution of inflammation and tissue repair after acute injury in inflammation but under pathological condition, the activation of RAGE has also been demonstrated in diabetes, atherosclerosis, nephropathy, neurodegeneration and can$\operatorname{cer}^{9,10}$. The effects of RAGE activation greatly depend on cell type and overall context but in the setting of limited nutrients or oxygenation, RAGE activation results in enhanced autophagy, diminished apoptosis, and (in the case of ATP depletion) necrosis ${ }^{6}$ with a potential role not only in inflammation but also in cancerogenesis and cancer $\operatorname{progression}^{10}$.

\section{Major RAGE ligands - AGEs, high mobility group B1 (HMGB1) and S100 proteins}

RAGE may be bound by many ligands which include advanced glycation endproducts (AGEs), certain members of the S100/calgranulin family, extracellular HMGB1 -amphoterin, the integrin Mac-1, amyloid beta-peptide and amyloid fibrils ${ }^{2,10}$. Serving as a counter-receptor for leukocyte integrins ( $\beta-2$ integrins) RAGE may also play an important role in cell adhesion and clustering as well as recruitment of inflammatory cells ${ }^{11}$. Other important ligands for RAGE may be glycosaminoglycans (including chondroitin sulfate, dermatan sulfate and heparan sulfate) which are frequently attached to proteoglycans on the surface of cancer cells and play an important role in the malignant transformation of the tumor and me$\operatorname{tastasis}^{12}$. Lysophosphatidic acid regulates proliferation, survival, motility and invasion of cells. Lysophosphatidic acid avidly binds to RAGE and RAGE is required for its signaling ${ }^{13}$ and phosphorylation of Akt and cyclin D, which may result in promoting carcinogenesis. Although these ligands are chemically very different they all share a negative charges on their surface and have a tendency to oligomerize ${ }^{2}$. 
AGEs are formed by nonenzymatic glycation and during oxidative and carbonyl stress and, they represent a heterogeneous group of compounds ${ }^{14}$. Highly reactive cabonyl compounds (e.g. methyglyoxal, glyoxal, 3-deoxyglucoson) whose increase is characteristic for carbonyl stress are generated via oxidative and non-oxidative pathways and are precursors of AGEs. Pentosidine, carboymethyllysine (CML) are methylglyoxallysine dimer (MOLD) and are the best known AGE-products. AGEs modify proteins. Some of them cause crosslinking, and have toxic effects via binding to specific receptors, of which RAGE is the best known. Food and tobacco smoke represent exogenous sources of AGEs. AGEs may be degraded on their binding to RAGE (ref. ${ }^{15}$ ) and some of their deleterious vasuclar effects may be also mediated by RAGE.

The high mobility group box 1 (HMGB1) protein is an abundant non-histone component of chromatin wellknown for its two DNA binding domains, HMG box A and HMG box B. The main characteristics of the HMGB1 protein as an "architectural" factor, are its ability to recognize and bind with high affinity to distorted DNA and its ability to induce kinks in linear DNA fragments ${ }^{11,16,17}$. HMGB1 plays important intranuclear, cytosolic and extracellular roles in the regulation of autophagy ${ }^{18}$, a degradation of namely dysfunctional organelles and proteins to generate metabolic fuels during starvation.

Although loosely bound to chromatin, HMGB1 can be either passively released from necrotic, but not apoptotic cells, or actively secreted by activated macrophages in a partially tumor necrosis factor-dependent manner, or in response to inflammatory and angiogenic signals. HMGB1 interacts with RAGE on endothelial cells causing activation and leukocyte recruitment ${ }^{16}$. HMGB 1 correlates with the inflammatory response and may also act as an endogenous pyrogen ${ }^{11}$ and may function as a cytokine, differentiation ${ }^{16}$ and proangiogenetic factor ${ }^{19}$.

HMGB1 can activate both TLRs (TLR2 and TLR4) and RAGE resulting in increased production of inflammatory mediators, but its main signaling pathway is activated through the interaction with RAGE (ref. ${ }^{20}$ ) resulting in the activation of NF- $\mathrm{B}$ further promoting inflammation ${ }^{19}$ in a positive feedback loop and contributing thus to sustaining inflammation and angiogenesis under different pathological conditions.

HMGB 1 has been implicated in different disease states, including Alzheimer's disease, sepsis, ischemia-reperfusion, arthritis, and cancer and targeting the HMGB1 ligand or its receptor may have important potential application in the treatment of these diverse pathological conditions.

The S100 protein family is the largest subgroup within the superfamily of proteins carrying the Ca2+-binding EFhand motif expressed only in vertebrates ${ }^{21}$ with a plethora of tissue-specific intra- and extracellular functions.

The S100 protein family consists of 24 members involved within the cells in the regulation of proliferation, differentiation, apoptosis, calcium homeostasis, energy metabolism, inflammation and migration/invasion interacting with a variety of target proteins, e.g. enzymes, cytoskeletal subunits, transcription factors and nucleic ac-

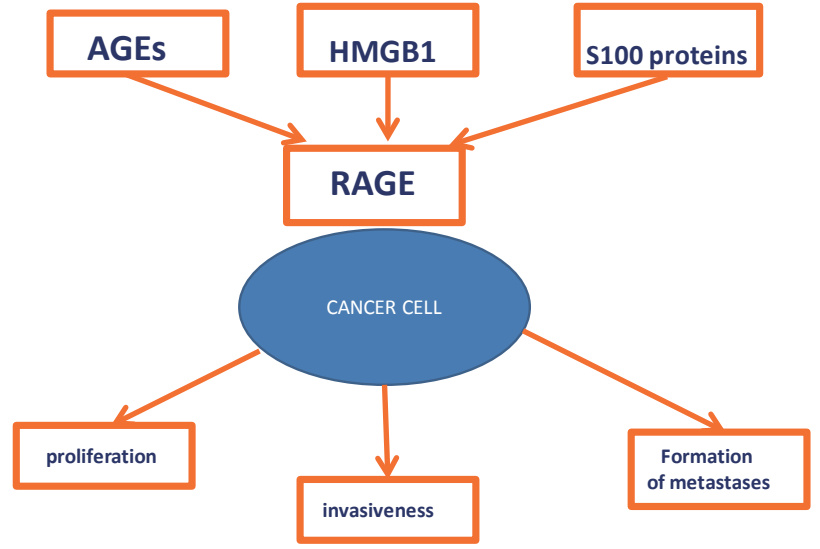

Fig. 1. Activation of RAGE in cancer and its putative consequences.

$\mathrm{ids}^{22}$. Some S100 proteins may be released or secreted and regulate cell functions in an autocrine and paracrine manner via different cell surface receptors (including RAGE and TLR4, or G-protein-coupled receptors) on many cell types (e.g. macrophages, endothelial and epithelial and vascular smooth muscle cells) and interact with heparan sulfate proteoglycans and N-glycans. S100A4 and S100B interact also with epidermal growth factor (EGF) and basic fibroblast growth factor (FGF2) enhancing the activity of their receptors. S100 proteins participate in regulating both innate and adaptive immunity, chemotaxis and cell migration, tissue development and repair and also leukocyte and tumor cell invasion. S100 proteins are thus implicated in the pathogenesis of many diseases, including inflammatory and neurodegenerative diseases and cancer.

\section{AGEs, their metabolism and cancer}

Activation of RAGE by AGEs was shown to stimulate growth and/or migration of pancreatic cancer, melanoma and breast cancer cells ${ }^{23}$. In the case of breast cancer cells, this effect canbe completely prevented by metformin ${ }^{23}$ (Table 1).

Elevated levels of $\mathrm{N} \varepsilon$-carboxymethyllysine (CML) were asociated with increased risk of pancreatic cancer but this relation was attenuated after adjustment for body mass index and smoking ${ }^{24}$. In a large study in a prospectively followed Finnish population CML-AGE and soluble RAGE (sRAGE) concentrations were inversely associated with liver cancer ${ }^{25}$. Unexpected negative association between CML-AGE and the risk of liver cancer is difficult to explain (CML-AGE may not be an optimal indicator of overall AGE production. Other RAGE ligands, e.g. HMGB 1 may be more important in activating RAGE in this setting). In another large prospective cohort of the Finnish male smokers, low sRAGE, but not high CMLAGE was associated with increased risk of colorectal cancer ${ }^{26}$.

Serum levels of AGEs and also AOPP (advanced oxidation protein products) were also increased in patients with breast cancer compared to controls ${ }^{27,28}$ even in the early stages (stage I and II) of the disease. Patients with advanced breast cancer (stage III and IV) had higher se- 
rum levels of both AGEs and AOPP not only compared to controls, but also to patients in early stages of the disease suggesting a role of carbonyl and oxidative stress in malignant transformation and progression of breast cancer.

In conclusion, although AGEs/RAGE interaction was shown to stimulate cancer cell proliferation available clinical data do not demonstrate AGEs (at least CML-AGEs) to be a good marker of the risk of either colorectal or liver cancer, although they may be related to the progression of breast cancer. The role of AGEs (and their activation of RAGE) remains to be established and the putative role of confounding factors (diabetes, impaired renal function) needs to be taken into consideration.

Impaired metabolim of AGEs may also play an important role in cancer. Methylglyoxal, a precursor of AGEs and potent inducer of apoptosis, may be degraded by the system of glutathione-dependent glyoxalases composed of glyoxalase I (Glo I) and glyoxalase II (Glo II) enzymes. Glyoxal and methylglyoxal bind to DNA and induce multibase deletions and base-pair substitutions, mostly occurring at $\mathrm{G}: \mathrm{C}$ sites $^{29}$ (Table 1). Glyoxalase may be activated in chronic inflammatory diseases and in diabetes and uremia to counteract the increased carbonyl and oxidative stress with the overproduction of AGEs, ALEs and AOPP (ref. ${ }^{14}$ ). S100A12, a RAGE ligand may decrease the expression of glyoxalase I and impair the degradation of $\mathrm{AGEs}^{30}$.

Mutations arising from DNA glycation could explain the link of carbohydrate intake to incidence of colorectal cancer and increased risk of cancer in patients with diabetes $^{29}$. Suppression of nucleotide glycation by glyoxalase I protects DNA not only in normal, but also in cancer cells from damage and contributes to its recovery and experimental overexpression of glyoxalase I confers the cancer cells with resistance to drug-induced apoptosis ${ }^{31}$. Small cell-permeable glyoxalase inhibitors were shown to counteact drug resistance in lung and prostate cancer ${ }^{31}$.

Alterations in the expression of the glyoxalase genes have been reported in several human cancers. Amplification of glyoxalase 1 gene was demonstrated in some tumours (e.g. in invasive ovarian and breast cancer ${ }^{29}$, especially drug-resistant tumour cell lines and increased glyoxalase 1 expression may be induced by malignant transformation and antitumour treatment, possibly supporting the viability of cancer cells with high glycolytic rates. In breast cancer, glyoxalase gene expression may be induced by $17 \beta$-estradiol (probably due to the presence of estrogen response element in the glyoxalase gene) resulting in much higher activity of both glyoxalases I an II in cancer compared to normal breast tissue ${ }^{32}$. Glyoxalase I was also overexpressed in the majority of patients with breast cancer and its upregulation correlated with advanced tumor grade ${ }^{33}$.

The activity of glyoxalase I may be modulated by various polyphenols, e.g. curcumin is a strong competitive inhibitor of glyoxalase I with concomitant antiinflammatory activity ${ }^{34}$. Curcumin was shown to inhibit the growth of breast and prostate cancer and brain astrocytoma and could be a promising anticancer compound. Resistence to doxorubicine in leukemia cells associated with increased glyoxalase I activity may be counteracted by the administration of thiazolidinedione troglitazone which downregulates glyoxalase I expression ${ }^{35}$.

Some cancers are associated with high glyoxalase activity which may contribute to the progression and resistance to chemotherapy. Some small cell permeable glyoxalase I inhibitors (e.g. polyphenols, PPAR $\gamma$ agonists) could be a good adjunct treatment in different types of cancer.

Polymorphism of glyoxalase I was studied in several types of cancer. We studied the Glu111Ala polymorphism of glyoxalase I in patients with breast cancer ${ }^{36}$ and were able to show that the higher frequency of the mutated $\mathrm{C}$ allele was found in patients with negative estrogen receptors and in patients and more advanced disease (clinical stage III) compared to controls $(P<0.05)$ suggesting that the presence of the $\mathrm{C}$ allele could be a negative prognostic factor in breast cancer. In a large Italian study of patients with breast cancer cancer ${ }^{37}$ polymorphism of glyoxalase I was associated with breast cancer in univariate analysis but a number of confounding factors obfuscate the results. In another large study in Malaysian patients with breast cancer $^{38}$ the genotype and allele frequencies of Ala $111 \mathrm{Glu}$ glyoxalase I polymorphism were not significantly different for patients and controls. The Glu allele genotype, was, however, associated with the absence of progesterone receptor. No difference in allelic and genotype frequencies of glyoxalase I gene was found in patients with pancreatic cancer $^{39}$. Very recently in a large study, Ala111Glu glyoxalase polymorphism was shown to be associated with clear cell renal cancer and RAGE polymorphisms (-429T/C and $2184 \mathrm{~A} / \mathrm{G}$ ) with its aggressiveness ${ }^{40}$.

The role of glyoxalase gene polymorphisms in cancer thus remain uncertain, but impaired glyoxalase activity may be associated with clear cell renal cancer and with outcome in breast cancer. Further studies are to elucidate the role of glyoxalase in cancer are therefore warranted.

\section{HMGB1 and cancer}

HMGB1 released from necrotic cancer cells (e.g. due to chemotherapy) may stimulate (through RAGE) the proliferation of the remnant cancer cells and metastasis contributing to the resistance to cancer therapy. In the mouse colon cancer model, lung and liver metastasis after doxorubicin treatment were abrogated by antiHMGB 1 treatment ${ }^{41}$ (Table 1). Tumor cells require ATP to support their proliferation. HMGB1-RAGE enhance tumor cell mitochondrial complex I activity, ATP production, tumor cell proliferation and migration. In the experimental setting, blockade of RAGE, or inhibition of HMGB1 release diminish ATP production and retard tumor growth ${ }^{42}$. $\mathrm{CpG}$ oligodeoxynucleotides enhance the growth and invasive potential of lung cancer cells. Cpg oligodeoxynucleotides stimulate the secretion of HMGB1 and blockade of extracellular HMGB1 abrogated the $\mathrm{CpG}$ oligodeoxynucleotides-induced progression of cancer cells. Activation of both TL4 and RAGE was critical for the response to HMGB1 in this mode ${ }^{43}$. 
Table 1. Types of cancer associated with RAGE ligands and their putative effects.

Type of cancer

RAGE ligand

Lung cancer S100A4, S100A6 and RAGE expressed in lung cancer, S100P detected in lung cancer associated with malignant phenotype, hormone independence and resistance to chemotherapy, progression and metastasis possibly through autocrine RAGE-mediated signaling (ref. ${ }^{52,57}$ )

Colorectal Highest quintile of CML-AGE not associated with an increased risk of colorectal cancer, HMGB1 and its receptors cancer overexpressed in colon cancer and associated with the proliferation and metastasis, S100P detected in colon cancer associated with malignant phenotype, resistance to chemotherapy, progression and metastasis possibly through autocrine RAGE-mediated signaling, S100P may promote the development of colon cancer, S100A4 prognostic biomarker of the formation of distant metastases and reduced overall and metastasis-free survival (ref. ${ }^{19,26,57,54,60}$ )

Hepatocellular CML-AGE (and sRAGE) concentrations inversely associated with liver cancer, HMGB1 levels increase after cancer transarterial chemoembolization of liver cancer $\left(\right.$ ref. $\left.^{25,49}\right)$

Pancreatic AGEs shown to stimulate through RAGE growth and/or migration of pancreatic cancer, elevated prediagnostic cancer levels of CML asociated with increased pancreatic cancer risk, no difference in polymorphisms of GLO genes in pancreatic cancer compared to controls, S100P detected in pancreas cancer associated with malignant phenotype, hormone independence and resistance to chemotherapy, progression and metastasis possibly through autocrine RAGE-mediated signaling, S100 proteins (namely S100A11 and S100P) involved in the progression and metastases of pancreatic cancer and associated with poor outcome after surgical resection, expression of S100A4 and S100P associated with drug resistence, differentiation, metastasis and clinical outcome (ref. ${ }^{23,24,39,57,61}$ )

Kidney cancer EN-RAGE related to obesity status in renal cancer, upregulated in tumor tissue of clear cell renal cancer, especially in pts with poorer overall survival and related to obesity status, Ala111Glu polymorphism linked to clear cell renal cancer (ref. ${ }^{40,71}$ )

Prostate HMBG1 co-expressed with RAGE in the prostatectomy specimens from a majority of pts with metastatic prostate cancer cancer, S100P detected in breast, prostate, pancreas, lung and colon cancer associated with malignant phenotype, hormone independence and resistance to chemotherapy, progression and metastasis possibly through autocrine RAGE-mediated signaling, S100A4 expression related to progreesion of prostatic cancer in the mouse model, S100A8 and S100A9 (and RAGE) expresssion enhanced in human prostate cancer and both proteins secreted by prostate cancer cells, serum levels of S100A9 increased in prostate cancer compared to benign prostatic hyperplasia (ref. ${ }^{46,55,57,65,66}$ )

Ovarian Glyoxalase 1 gene amplified in invasive ovarian cancer and glyoxalase 1 may play a role in multidrug resistance cancer $\quad\left(\right.$ ref. $\left.{ }^{29}\right)$

Breast cancer AGEs induced proliferation of breast cancer cells could have been completely prevented by metformin, Glyoxalase 1 gene amplified in breast cancer and glyoxalase 1 may play a role in multidrug resistance, glyoxalase expression influenced by $17 \beta$-estradiol, Glyoxalase I is overexpressed in breast cancer and its expression correlates with tumor grade, higher frequency of $\mathrm{C}$ allele in Glu111Ala polymorphism of glyoxalase I found in patients with breast cancer and negative estrogen receptors and patients with more advanced disease, no association of Glu111Ala polymorphism of glyoxalase I in Malaysian patients, polymorphism, however, associated with the absence of progesterone receptor, polymorphism of glyoxalase I associated with increased risk of breast cancer, HMGB1 and its receptors overexpressed in breast cancer and associated with the proliferation and metastasis, serum levels of HMGB1 decreased compared to controls in pts with metastatic breast cancer, pts with no response to neoadjuvant chemotherapy tended to have compared to pts achieving complete or partial remission higher HMGB1, S100A4, S100A6 and RAGE expressed in breast cancer, S100P detected in breast cancer associated with malignant phenotype, hormone independence and resistance to chemotherapy, progression and metastasis possibly through autocrine RAGE-mediated signaling, S100A7/psoriasin overexpressed in invasive, estrogen receptor negative breast cancer and may contribute to its prolilferation, angiogenesis and metastasis, S1007 expressed already in high-grade ductal carcinoma in situ and high-grade comedo ductal carcinoma in situ with a higher risk of local recurrence, S100A8/A9 binding of RAGE may promote the invasion of breast cancer cells and associated with lymph node involvement and distant (lung) metastases ( ref. $^{19,23,29,32,33,36-38,48,52,57,62-65}$ )

Melanoma AGEs shown to stimulate through RAGE growth and/or migration of melanoma cells, HMGB1 and its receptors overexpressed in melanoma and associated with the proliferation and metastasis, S100A4 secreted by tumorassociated macrophages may contribute to the progression of melanoma and increase metastatic potential of melanoma cells, S100A8/S100A9 (calprotectin) may stimulate migration of melanoma cells by the RAGE-independent mechanism, S100B overexpressed in melanoma and reliable prognostic biomarker (ref. ${ }^{19,23,56,67,70}$ ) 
Table 1. continued

\begin{tabular}{|c|c|}
\hline Type of cancer & RAGE ligand \\
\hline Brain tumors & $\begin{array}{l}\text { HMGB1 released from necrotic cells induces proliferation and migration in human malignant glioma cells, S100B } \\
\text { overexpressed by gliomas, its expression related to the infiltration with tumor-associated macrophages, inflam- } \\
\text { matory response and increased vascularity, these effect may not be mediated by RAGE, but possibly through } \\
\text { CCL2 }\left(\text { ref }^{45,69}\right)\end{array}$ \\
\hline $\begin{array}{l}\text { Chronic } \\
\text { lymphatic } \\
\text { leukemia }\end{array}$ & $\begin{array}{l}\text { Drug resistance in leukemia cells asociated with upregulation of glyoxalase I, HMGB1 levels increased in pts with } \\
\text { CLL and HMGB1 concentration associated with absolute lymphocyte cell count, CLL cells passively release } \\
\text { HMGB1, release of HMGB1 related to the differentiation of nurse-like cells (NLC), S100A8 promotes (through } \\
\text { RAGE activation) autophagy of leukemia cells and contributes to the drug resistance of leukemia cells (ref. }{ }^{35,47} \text { ) }\end{array}$ \\
\hline Lymphoma & S100A2 expression observed in lymphoma biopsies (ref. ${ }^{52}$ ) \\
\hline
\end{tabular}

HMGB 1 and its receptors are widely overexpressed (and its protein levels increased) in virtually every examined type of cancer ${ }^{19}$ and its overexpression was (usually in parallel with the overexpression of RAGE) associated with the proliferation and metastasis of many tumor types, including breast, colon, melanoma, and others. On the other hand, data on the relation of HMGB1 to the histological grade of the tumor are very limited ${ }^{44}$. In human malignant glioma cells, HMGB1 induced a dosedependent increase in cell proliferation and cell migration. In glioma cells (as in other types of cancer) HMGB1 is predominantly bound in the nucleus and is released only by necrotic glioma cells (e.g. after chemotherapy or radiotherapy ${ }^{45}$ ).

The HMGB1 protein has been correlated to cancer progression, especially invasion and metastasis in melanoma, colon, prostate, pancreatic and breast cancer ${ }^{17}$. HMBG1 is co-expressed with RAGE in the prostatectomy specimens from a majority of patients with metastatic prostate cancer, but in only less than a quarter of nonmetastatic prostate cancers. The invasive capacity of prostate cancer cells could have been suppressed in vitro with HMGB1 antisense S-oligodeoxynucleotide, but, on the other hand, HMGB1 secretion was induced by androgen deprivation $^{46}$.

HMGB1 may be an important survival factor for malignat B cells in chronic lymphocytic leukemia (CLL). HMGB1 levels are increased in patients with CLL compared to controls and are associated with absolute lymphocyte cell count. CLL cells are able to passively release HMGB 1 and this release is related to the differentiation of nurse-like cells (promoting growth of malignant lymphocytes) which can be blocked by inhibiting RAGE and TLR9 $\left(\right.$ ref. $^{47}$ ).

In another study, serum levels of HMGB1 were lower (in parallel with sRAGE) in patients with metastatic breast cancer compared to controls ${ }^{48}$, but patients with no response to neodajuvant chemotherapy tended to have, compared to patients achieving complete and partial remission, higher HMGB 1 and lower sRAGE levels before therapy suggesting that both parameters could serve as prognostic markers of therapeutic response.

HMGB1 levels increase early after transarterial chemoembolization of liver cancer, but the response to this treatment is not associated with high HMGB1, but low sRAGE levels ${ }^{49}$.
HMGB1 thus seems to play an important role in the stimulation of the proliferation of cancer cells, especially after previous chemotherapy. Except for competitive antagonists of HMGB1, HMGB 1 may be also bound by a range of small natural or synthetic molecules, e.g. glycyrrhizin, or gabexate mesilate and neutralized by HMGB1-specific antibodies ${ }^{50}$. The putative role of these interventions in the treatment of different types of cancer remains to be established.

\section{S100 proteins and cancer}

S100 proteins may play a role in different stages of tumorigenesis including cell differentiation, cell cycle regulation, cell growth, apoptosis, cell motility, migration, invasiveness and metastasis formation and also tumor microenvironment ${ }^{51}$.

Expression of different S100 proteins was demonstrated in tumour cells and may be specific for different types of cancer. Using microarray technology to study S100 protein expression in tumor samples, S100A2 expression was observed in lymphoma biopsies, S100A4 and S100A6 (in parallel with RAGE) was abundant in breast and lung tumours $^{52}$ (Table 1).

S100A4 was secreted by both tumor and stromal cells in melanoma xenograft model and supported (via RAGE) tumorigenesis and angiogenesis synergizing with vascular endothelial growth factor (VEGF) and also promoting endothelial cell migration by increasing MMP-9 activity. Endothelial cell migration, tumor growth and angiogenesis could have been abolished in this mode by the administration of anti-S100A4 monoclonal antibody ${ }^{53}$. S100A4 increased cell migration and invasion also in colon cancer cells and this effect may have been counteracted by soluble RAGE and anti-RAGE antibodies ${ }^{54}$. S100A4 also progresssively increased in prostatic tissue with the progression of the disease in the mouse model of prostate cancer and S100A4 cancer cells grew more quickly (via RAGE and NFkB activation) than S100A4 negative cells ${ }^{55}$. As heterozygously deleted S1004 mice exhibited an increased tumor latency period, reduced prostatic weights and no metastases S100A4 inhibition could be a promising therapeutic option to be tested in prostate cancer. S100A4 may be synthesized not only by tumor, but also by stroma cells. In melanoma, infiltrating tumor-associated macrophages may also secrete S100A4 
Table 2. Putative interference with RAGE ligands and RAGE-mediated effect.

\begin{tabular}{|c|c|c|c|}
\hline Mechanism & Type of cancer & Effect & Ref. \\
\hline Metformin & Breast cancer & $\begin{array}{l}\text { Decreased incidence and better survival in diabetic pts with } \\
\text { breast cancer treated with metformin }\end{array}$ & $\begin{array}{l}23 \\
75\end{array}$ \\
\hline Thiazolidinediones & Breast cancer & $\begin{array}{l}\text { Better survival in diabetic pts with breast cancer treated with } \\
\text { thiazolidinediones }\end{array}$ & 75 \\
\hline PPARy agonists & $\begin{array}{l}\text { Not yet shown in } \\
\text { cancer }\end{array}$ & Interference with the AGE-RAGE system & 74 \\
\hline Cromolyn & $\begin{array}{l}\text { Pancreatic } \\
\text { cancer (ductal } \\
\text { adenocarcinoma) }\end{array}$ & Inhibition of S100P-induced cell growth & 76 \\
\hline Pravastatin & $\begin{array}{l}\text { Not yet shown } \\
\text { in cancer }\end{array}$ & $\begin{array}{l}\text { Dose-dependent inhibition of AGE-mediated upregulation of } \\
\text { RAGE }\end{array}$ & 23 \\
\hline Irbesartan & $\begin{array}{l}\text { Not yet shown } \\
\text { in cancer }\end{array}$ & Inhibition of AGE-induced upregulation of RAGE & 73 \\
\hline $\begin{array}{l}\text { Heparin }(\mathrm{O}, 3-\mathrm{O}-\text { desulfated } \\
\text { heparin - ODSH) }\end{array}$ & & $\begin{array}{l}\text { Inhibition of RAGE interaction with CD11b/CD18 (Mac-1) and } \\
\text { inhibition of its activation by many ligands (AGEs, HMGB1, } \\
\text { S100 calgranulins), reduction of selectin-mediated lung metasta- } \\
\text { sis of melanoma in mice }\end{array}$ & 77 \\
\hline $\begin{array}{l}\text { Antibodies against chondroi- } \\
\text { tin sulfate }(\mathrm{CS}) \text {, or CS-E }\end{array}$ & Lung cancer & Inhibition of metastasis & 78 \\
\hline Antibodies against RAGE & $\begin{array}{l}\text { lung cancer, } \\
\text { melanoma cells }\end{array}$ & Inhibition of metastasis formation & 12 \\
\hline Recombinant soluble RAGE & Hepatic cancer & $\begin{array}{l}\text { sRAGE may protect against RAGE- induced tissue damage by } \\
\text { neutralizing its ligands }\end{array}$ & 79 \\
\hline $\begin{array}{l}\text { Small S100P-derived RAGE } \\
\text { antagonist (RAP) }\end{array}$ & $\begin{array}{l}\text { Pancreatic cancer, } \\
\text { glioma }\end{array}$ & $\begin{array}{l}\text { RAP may block activation of RAGE by multiple ligands and } \\
\text { inhibits interaction of S100P, S100A4 and HMGB1 with RAGE, } \\
\text { administration of RAP results in reduction of growth and metas- } \\
\text { tasis of pancreatic cancer and inhibition of glioma growth }\end{array}$ & 76 \\
\hline RAGE-siRNA & Breast cancer & Decrease in proliferation of breast cancer cells & 81 \\
\hline Anti-HMGB-1 antibodies, & & Blocking extracellular effects of HMGB-1 & 80 \\
\hline $\begin{array}{l}\text { HMGB-A box (competitive } \\
\text { antagonist of HMGB1) }\end{array}$ & & Blocking release of HMGB-1 from the nucleus & 80 \\
\hline Anti-TLR2 antibody & & Blocking HMGB1 signaling through TLR2 & 80 \\
\hline Soluble thrombomodulin & & Modulation of HMGB-1 activity & 80 \\
\hline
\end{tabular}

and in this paracrine manner increased the metastatic potential of melanoma cells ${ }^{56}$.

Expression of another member of the S100 family, $\mathrm{S} 100 \mathrm{P}$, was detected in a spectrum of human tumor cell lines and tissues derived from breast, prostate, pancreas, lung and colon, where it was connected with malignant phenotype, hormone independence,resistance to chemotherapy and metastasis ${ }^{57}$. S100P was shown to stimulate RAGE and increase proliferation and prolong survival of cancer cells in an autocrine manner ${ }^{58}$ Its effects can be blocked by anti-RAGE antibodies. S100-P derived small antagonistic peptides could be potentially used to block tumor proliferation ${ }^{59}$. In colon cancer cells elevated S100P stimulated RAGE, AP-1 and induced oncogenic miR-155 and S100P-induced proliferation, motility and invasion may have been blocked either by anti-RAGE antibodies, or miR-155 knockdown ${ }^{60}$.

In pancreatic cancer, the expression of S100A4 and S100P was associated with drug resistence, differentiation, metastasis and clinical outcome and S100A11 and S100P, and possibly also S100A2 and S100A6 were related to the unfavorable outcome of the patients after surgical resection ${ }^{61}$.

S100A7/psoriasin was highly expressed in high-grade ductal breast carcinoma in $\operatorname{situ}^{62}$, high-grade comedo ductal carcinoma in situ with higher risk of local recurrence ${ }^{63}$ and in invasive estrogen receptor negative breast cancer ${ }^{64}$. Its expression was related to ductal hyperplasia, recruitment of tumor-associated macrophages, tumor growth, angiogenesis and metastasis. Tumor growth was inhib- 
ited by the downregulation of psoriasin by short hairpin RNA (shRNA) resulting in decreased expression of vascular endothelial growth factor (VEGF) $\left(\right.$ ref. $\left.^{62}\right)$. Invasion of breast cancer may be also stimulated by S100A8/A9 via RAGE-mediated epithelial-mesenchymal transition through NF-kB mediated stabilization of Snail. In invasive ductal carcinoma S100A8/A9 binding is associated with lymph node involvement and distant (lung) metastases ${ }^{65}$.

Deregulated expression of different S100 proteins, e.g. S100A8 and S100A9, is associated with different neoplastic disorders. S100A8 and S100A9 expresssion is enhanced in human prostate cancer and are secreted by prostate cancer cells ${ }^{66}$. Extracellular S100A8 and S100A9 activate RAGE, induce the activation of NF- $\mathrm{KB}$ and increased phosphorylation of p38 and p44/42 MAP kinases and stimulate migration of benign prostatic cells in vitro. S100A8, S100A9 and RAGE are co-expressed and upregulated in prostatic intraepithelial neoplasia and preferentially in high-grade adenocarcinomas but not in benign prostatic tissue. Serum levels of S100A9 may help to distinguish between prostate cancer and benign prostatic hyperplasia ${ }^{66}$

S100A8 and S100A9 may dimerize and form calprotectin. Cell surface glycoprotein EMMPRIN/BASIGIN (CD147/BSG) may serve as a receptor for calprotectin and was demonstrated to specifically bind S100A9 and induction of cytokines, matrix metalloproteinases and cell migration by S100A9 may be downregulated in melanoma cells by attenuation of EMMPRIN independently of RAGE $^{67}$.

S100A8 are elevated in drug-resistant leukemia cell lines and may play an important role in the drug resistance of leukemia cells by promoting autophagy. Adriamycine and vincristine increase S100A8 in human leukemia cells in parallel with the upregulation of autophagy ${ }^{68}$. Knockdown of S100A8 induced by RNA interference restored the chemosensitivity of leukemia cells. S100A8 could be thus a novel therapeutic target for improved drug sensitivity in leukemia therapy.

$\mathrm{S} 100 \mathrm{~B}$ is overexpressed by gliomas and its downregulation of S100B abrogates tumor growth in vivo and is related to higher infiltration with tumor-associated macrophages, stronger inflammatory response and increased vascularity. As RAGE ablation had no effect on the infiltration of gliomas with tumor-associated macrophages, other pathways (possibly CCL2 expression) may be involved and could be targeted ${ }^{69}$. S100B expression may also be a prognostic marker in malignant melanoma ${ }^{70}$.

S100A12 (ENRAGE) is related to obesity status in clear cell renal cancer (which is a risk factor of this type of cancer) and is overexpressed in tumor tissue, especially in patients with poorer overall survival. S10012 may serve through the activation of RAGE as an autocrine stimulator of the tumor growth ${ }^{71}$.

\section{Targeting RAGE and its ligands - can it contribute to the treatment of breast cancer?}

The activity of RAGE and its ligands may be suppressed in many possible way using both small molecules, monoclonal antibodies, or siRNAs (Table 2).
Both statins $^{72}$ and angiotensin receptor blockers ${ }^{73}$ inhibit RAGE signaling in diabetic nephropathy, but no data on their putative effect on RAGE activation in cancer are available. Metformin use may decrease the incidence and mortality in breast cancer by inhibition of AGEs induced proliferation of breast cancer cells ${ }^{23}$. Peroxisome proliferator-activated receptor-gamma (PPARgamma) agonists were also shown to interfere with the AGE-RAGE system $^{74,75}$. Antiallergic drug cromolyn and its derivatives may block the interaction of S100P with RAGE and high concentrations of cromolyn were shown to improve gemcitabine effectiveness in pancreatic ductal adenocarcinoma by inhibiting S100P- induced increase of NF- $\kappa$ B, cell growth and apoptosis and cromolyn derivatives may be promising drugs to block S100P in different types of cancer ${ }^{76}$.

Heparin and its low anti-coagulant derivative 2-0,3-0-desulfated heparin disrupt CD11b/CD18 mediated leukocyte adhesion to RAGE and inhibited activation of RAGE by AGEs, HMGB1 and S100 proteins. These heparins with low anticoagulant activity were also able to prevent metastases ${ }^{77}$. Altered expression of chondroitin sulfate (CS - with higher proportion of E-disaccharide units) on the surface of tumor cells may contribute to malignant transformation and metastasis which canbe inhibited in lung cancer cells by pre-administration of CS-E from squid cartilage rich in $\mathrm{E}$ units or antibodies against CS-E interfering with CS-RAGE signaling suggesting a putative role of these approaches in the treatment of pulmonary metastasis ${ }^{78}$.

AGEs induced proliferation of breast cancer cells could be completely prevented by anti-RAGE antibodies $^{23}$. Antibodies against RAGE were also shown to inhibit metastasis of experimental lung cancer and melanoma cells $^{12}$. Administration of recombinant soluble RAGE was shown to block RAGE signaling pathway in animal models, suggesting that the circulating sRAGE could protect the tissue againgst RAGE-induced tissue damage ${ }^{79}$ and sRAGE could serve also in cancer as a putative biomarker.

HMGB-1 can be blocked in several different ways ${ }^{80}$ : by anti-HMGB-1 antibodies, by the inhibition of HMGB1 release from the nucleus into the extracellular space, by HMGB-A box, a competitive antagonist of HMGB-1, by blockage of RAGE-HMGB-1 signaling using RAGE antagonists, by blockage of TLR-HMGB-1 signaling using anti-TLR2 antibodies and by other molecules that modulate HMGB-1 activity using e.g. human soluble thrombomodulin.

The recently developed small S100P-derived RAGE antagonist peptide (RAP) blocking activation of RAGE by multiple ligands was shown to inhibit the interaction of S100P, S100A4, and HMGB-1 with RAGE at micromolar concentrations. Systemic in vivo administration of RAP reduced the growth and metastasis of pancreatic tumors and also inhibited glioma tumor growth ${ }^{76}$.

Decrease in the proliferation of different types of experimental breast cancer with increased RAGE expression (correlating with the severity of breast cancer) could have been induced by small interfering RNA against RAGE (RAGE siRNA) (ref. ${ }^{81}$ ). 
Overall specific modes of RAGE inhibition and its ligands could be promising not only in diabetes and other inflammatory and neurodegenerative disorders but also in cancer.

\section{CONCLUSIONS}

The activity of the RAGE ligand(s)/RAGE system appears to be involved in a number of cancers contributing to the proliferation of cancer cells, their invasiveness, metastasis and resistence to treatment. Serum levels and tissue expression of RAGE and RAGE ligands may thus be useful biomarkers of diseaase severity and disease outcome and potential therapeutic targets. We believe that the role RAGE and its ligands in cancer will be a fruitful area for further research and will help our understanding of the pathogenesis of cancer progression and metastasis.

Acknowledgement: Our research was supported by the research projects RVO-VFN64615 of the Ministry of Health and the research project of Charles University P25/LF1/2. Author contributions: PT: clinical implications and interpretation of the data, MK and TZ: biochemistry of RAGE and interaction of RAGE with its ligands, VT: clinical implications of the data, literature search.

Conflict of interest statement: The authors declare that there are no conflicts of interest regarding the publication of this article.

\section{REFERENCES}

1. Sims GP, Rowe DC, Rietdijk ST, Herbst R, Coyle AJ. HMGB1 and RAGE in inflammation and cancer. Annu Rev Immunol 2010;28:367-88.

2. Fritz G. RAGE: a single receptor fits multiple ligands. Cell 2011;36:62532.

3. Lin L. RAGE on the Toll road? Cell Mol Immunol 2006;3:351-6.

4. Ibrahim ZA, Armour CL, Phipps S, Sukkar MB. RAGE and TLRs: relatives, friends or neighbours? Mol Immunol 2013;56:739-44.

5. Schmidt AM, Stern DM. Receptor for age (RAGE) is a gene within the major histocompatibility class III region: implications for host response mechanisms in homeostasis and chronic disease. Front Biosci 2001;6:D1151-60.

6. Sparvero LJ, Asafu-Adjei D, Kang R, Tang D, Amin N, Im J, Rutledge R, Lin B, Amoscato AA, Zeh HJ, Lotze MT. RAGE (Receptor for Advanced Glycation Endproducts), RAGE ligands, and their role in cancer and inflammation. JTransl Med 2009;17;7:17.doi: 10.1186/1479-5876-717.

7. Wautier JL, Zoukourian C, Chappey O, Wautier MP, Guillausseau PJ, Cao R, Hori O, Stern D, Schmidt AM. Receptor-mediated endothelial cell dysfunction in diabetic vasculopathy. Soluble receptor for advanced glycation end products blocks hyperpermeability in diabetic rats. J Clin Invest 1996;97:238-43.

8. Sterenczak KA, Nolte I, Murua Escobar H. RAGE splicing variants in mammals. Methods Mol Biol 2013;963:265-76.

9. Sorci G, Riuzzi F, Giambanco I, Donato R. RAGE in tissue homeostasis, repair and regeneration. Biochim Biophys Acta 2013;1833:101-9.

10. Raucci A, Cugusi S, Antonelli A, Barabino SM, Monti L, Bierhaus A, Reiss K, Saftig P, Bianchi ME. A soluble form of the receptor for advanced glycation endproducts (RAGE) is produced by proteolytic cleavage of the membrane-bound form by the sheddase a disintegrin and metalloprotease 10 (ADAM10). FASEB J 2008;22:3716-27.

11. Lotze MT, DeMarco RA. Dealing with death: HMGB1 as a novel target for cancer therapy. Curr Opin Investig Drugs 2003;4:1405-9.

12. Mizumoto S, Sugahara K. Glycosaminoglycans are functional ligands for receptor for advanced glycation end-products in tumors. FEBS J 2013;280:2462-70.

13. Rai V, Touré F, Chitayat $S$, Pei R, Song F, Li Q, Zhang J, Rosario R, Ramasamy R, Chazin WJ, Schmidt AM. Lysophosphatidic acid targets vascular and oncogenic pathways via RAGE signaling. J Exp Med 2012;209:2339-50.

14. Kalousova M, Zima T, Tesar V, Dusilova-Sulkova S, Skrha J. Advanced glycoxidation end products in chronic diseases - clinical chemismy and genetic background. Mutat Res 2005;579:37-46.

15. Stirban A, Gawlowski T, Roden M. Vascular effects of advanced glycation endproducts: clinical effects and molecular mechanisms. Mol Metab 2013;3:94-108.

16. Ellerman JE, Brown CK, de Vera M, Zeh HJ, Billiar T, Rubartelli A, Lotze MT. Masquerader: high mobility group box-1 and cancer. Clin Cancer Res 2007;13:2836-48.

17. Todorova J, Pasheva E. High mobility group B1 protein interacts with its receptor RAGE in tumor cells but not in normal tissues. Oncol Lett 2012;3:214-8.

18. Kang R, Livesey KM, Zeh HJ, Zeh HJ, Loze MT, Tang D. Metabolic regulation by HMGB1-mediated autophagy and mitophagy. Autophagy 2011;7:1256-8

19. Van Beijnum JR, Buurman WA, Griffioen AW. Convergence and amplification of toll-like receptor (TLR) and receptor for advanced glycation end products (RAGE) signaling pathways via high mobility group B1 (HMGB1). Angiogenesis 2008;11:91-9.

20. Nogueira-Machado JA, Volpe CM, Veloso CA, Chaves MM. HMGB1, TLR and RAGE: a functional tripod that lead to diabetic inflammation. Expert Opin Ther Targets 2011;15:1023-35.

21. Marenholz I, Heizmann CW, Fritz G. S100 proteins in mouse and man: from evolution to function and pathology (including an update of the nomenclature). Biochem Biophys Res Commun 2004; 322:111122.

22. Donato R, Cannon BR, Sorci G, Zeh HJ, Loze MT, Tang D. Functions of S100 proteins. Curr Mol Med 2013;13:24-57.

23. Ishibashi Y, Matsui T, Takeuchi M, Yamagishi S. Metformin inhibits advanced glycation end products (AGEs)-induced growth and VEGF expression in MCF-7 breast cancer cells by suppressing AGEs receptor expression via AMP-activated protein kinase. Horm Metab Res 2013;45:387-90.

24. Grote VA, Nieters A, Kaaks R, Tjønneland A, Roswall N, Overvad $K$, Nielsen MR, Clavel-Chapelon F, Boutron-Ruault MC, Racine A, Teucher B, Lukanova A, Boeing H, Drogan D, Trichopoulou A, Trichopoulos D, Lagiou P, Palli D, Sieri S, Tumino R, Vineis P, Mattiello A, Argüelles Suárez MV, Duell EJ, Sánchez MJ, Dorronsoro M, Huerta Castaño JM, Barricarte A, Jeurnink SM, Peeters PH, Sund M, Ye W, Regner S, Lindkvist B, Khaw KT, Wareham N, Allen NE, Crowe FL, Fedirko V, Jenab M, Romaguera D, Siddiq A, Bueno-de-Mesquita $\mathrm{HB}$, Rohrmann S. The associations of advanced glycation end products and its soluble receptor with pancreatic cancer risk: a casecontrol study within the prospective EPIC cohort. Cancer Epidemiol Biomarkers Prev 2012;21:619-28.

25. Moy KA, Jiao L, Freedman ND, Weinstein SJ, Sinha R, Virtamo J Albanes D, Stolzenberg-Solomon RZ. Soluble receptor for advanced glycation end products and risk of liver cancer. Hepatology 2013;57:2338-45.

26. Jiao L, Taylor PR, Weinstein SJ, Graubard BI, Virtamo J, Albanes $D_{\text {, }}$ Stolzenber-Solomon RZ. Advanced glycation end products, soluble receptor for advanced glycation end products, and risk of colorectal cancer. Cancer Epidemiol Biomarkers Prev 2011;20:1430-8.

27. Tesarova P, Kalousova M, Trnkova B, Soukupova J, Argalasova S, Mestek O, Petruzelka L, Zima T. Carbonyl and oxidative stress in patients with breast cancer - is there a relation to the stage of the disease? Neoplasma 2007;54:219-24.

28. Tesarova P, Kalousova M, Jachymova M, Mestek O, Petruzelka L, Zima T. Receptor for advanced glycation end products (RAGE) - soluble form (sRAGE) and gene polymorphisms in patients with breast cancer. Cancer Invest 2007;25:720-5.

29. Thornalley PJ. Protecting the genome: defence against nucleotide glycation and emerging role of glyoxalase I overexpression in multidrug resistance in cancer chemotherapy. Biochem Soc Trans 2003;31:1372-7.

30. Thornalley,PJ, Rabbani N. Highlights and hotspots of protein glycation in end-stage renal disease. Semin Dial 2009;22:400-4.

31. Thornalley PJ, Rabbani N. Glyoxalase in tumourigenesis and multidrug resistance. Semin Cell Dev Biol 2011;22:318-25. 
32. Rulli A, Antognelli C, Prezzi E, Baldracchini F, Piva F, Giovannini $\mathrm{E}$, Talesa $\mathrm{V}$. A possible regulatory role of $17 \mathrm{beta}$-estradiol and tamoxifen on glyoxalase I and glyoxalase II genes expression in MCF7 and BT20 human breast cancer cells. Breast Cancer Res Treat 2006;96:187-96.

33. Fonseca-Sánchez MA, Rodríguez Cuevas S, Mendoza-Hernández G, Bautista-Piña V, Arechaga Ocampo E, Hidalgo Miranda A, Quintanar Jurado V, Marchat LA, Alvarez-Sánchez E, Pérez Plasencia C, LópezCamarillo C. Breast cancer proteomics reveals a positive correlation between glyoxalase 1 expression and high tumor grade. Int J Onco 2012;41:670-80.

34. Santel T, Pflug G, Hemdan NY, Schafer A, Hollenbach M, Buchold M, Hintersdorf A, Lindner I, Otto A, Bigl M, Oerlecke I, Hutschenreuther A, Sack U, Huse K, Groth M, Birkemeyer C, Schellenberger W, Gebhardt R, Platzer M, Weiss T,Vijayalakshmi MA, Kruger M, Birkenmeier G. Curcumin inhibits glyoxalase 1: a possible link to its anti-inflammatory and anti-tumor activity. PLoS One 2008;3:e3508,doi: 10.1371/ journal.pone.0003508.

35. Davies GF, Juurlink BH, Harkness TA. Troglitazone reverses the multiple drug resistance phenotype in cancer cells. Drug Des Devel Ther 2009;3:79-88.

36. Germanova A, Germanova A, Tesarova P, Jachymova M, Zvara K, Zima T, Kalousova M. Glyoxylase I Glu111Ala polymorphism in patients with breast cancer. Cancer Invest 2009;7: 655-60.

37. Antognelli C, Del Buono C, Ludovini V, Gori S, Talesa VN, Crino L, Barberini F, Rulli A. CYP17, GSTP1, PON1 and GLO1 gen polymorphisms as risk factors for breast cancer: an Italian case-control study. BMC Cancer 2009;9:115,doi:10.1186/1471-2407-9-115.

38. Naidu R, Har YC, Taib NA. Glyoxylase I Glu111Ala gene polymorphism: no association with breast cancer risk but correlated with absence of progesterone receptor. Pathol Int 2010;60:614-20.

39. Krechler T, Jachymova M, Mestek O, Zak A, Zima T, Kalousova M Soluble receptor for advanced glycation end-products (sRAGE) and polymorphisms of RAGE and glyoxalase I genes in patients with pancreas cancer. Clin Biochem 2010;43:882-6.

40. Chocholaty M, Jachymova M, Schmidt M, Havlova K, Krepelova A, Zima T, Babjuk M, Kalousova M. Polymorphisms of the receptor for advanced glycation end-products and glyoxalase I in patients with renal cancer. Tumour Biol 2015;36:2121-6.

41. Luo Y, ChiharaY, Fujimoto K, Sasahira T, Kuwada M, Fujiwara R, Fuji $\mathrm{K}$, Ohmori $\mathrm{H}$, Kuniyasu $\mathrm{H}$. High mobility group box 1 released from necrotic cells enhances regrowth and metastasis of cancer cells that survived chemotherapy. Eur. J. Cancer 2013;49:741-51.

42. Kang R, Tang D, Schapiro NE. The HMGB1/RAGE inflammatory pathway promotes pancreatic tumor growth by regulating mitochondria bioenergetics. Oncogene 2014;33:567-77.

43. Wang C, Fei G, Liu Z, Li Q, Xu Z, Ren T. HMGB1 was a pivotal synergistic effector for $\mathrm{CpG}$ oligonucleotide to enhance the progression of human lung cancer cells. Cancer Biol 2012;13:727-36.

44. Kostova N, Zlateva S, Ugrinova I, Pasheva E. The expression of HMGB1 protein and its receptor RAGE in human malignant tumors. Mol Cell Biochem 2010;337:251-8.

45. Bassi R, Giussani P, Anelli V, Colleoni T, Pedrazzi M, Patrone M, Viani P, Sparatore B, Melloni E, Riboni L. HMGB1 as an autocrine stimulus in human T98G glioblastoma cells: role in cell growth and migration. J Neurooncol 2008;87:23-33.

46. Kuniyasu $H$, Chihara $Y$, Kondo H, Ohmori H, Ukai R. Amphoterin induction in prostatic stromal cells by androgen deprivation is associated with metastatic prostate cancer. Oncol Rep 2003;10:1863-8.

47. Jia L, Clear A, Liu FT, Matthews J, Uddin N, McCarthy A, Hoxha E, Durance C, Iqbal S, Gribben JG. Extracellular HMGB1 promotes differentiation of nurse-like cells in chronic lymphocytic leukemia. Blood 2014;123:1709-19.

48. Stoetzer OJ, Ferschning DM, Salat C, Steinkohl O, Gabka CJ, Hamann U, Braun M, Feller AM, Heinemann V, Siegele B, Nagel D, Holdenrieder $\mathrm{S}$. Circulating immunogenic cell death biomarkers HMGB1 and RAGE in breast cancer patients during neoadjuvant chemotherapy. Tumour Biol 2013;34:81-90.

49. Kohles $N$, Nagel $D$, Jungst $D$, Stieber $P$, Holdenrieder S. Predictive value of immunogenic cell death biomarkers HMGB1, sRAGE and Dnase in liver cancer patients receiving transarterial chemoembolization therapy. Tumour Biol 2012;33:2401-9.

50. Musumeci D, Roviello GN, Montesarchio D. An overview on HMGB inhibitors as potential therapeutic agents in HMGB1-related pathologies. Pharmacol Ther 2014;141:347-57.

51. Chen $\mathrm{H}, \mathrm{Xu} \mathrm{C}$, Jin Q, Liu Z. S100 protein family in human cancer. Am J Cancer Res 2014;4:89-115.

52. Hsieh HL, Schafer BW, Sasaki N, Heizmann CW. Expression analysis of S100 proteins and RAGE in human tumors using tissue microarrays. Biochem Biophys Res Commun 2003;307:375-81.

53. Hernandez JL, Padilla L, Dakhel S, Coll T, Hervas R, Adan J, Masa M, Mitjans F, Martinez JM, Coma S, Rodriguez L, Noe V, Ciudad CJ, Blasco $\mathrm{F}$, Messeguer $\mathrm{R}$. Therapeutic targeting of tumor growth and angiogenesis with a novel anti-S100A4 monoclonal antibody. PLoS One 2013,8: e72480,doi: 10.1371/ journal.pone.0072480.

54. Dahlmann M, Okhrimenko A, Marcinkowski P, Osterland M, Herrmann P, Smith J, Heizmann CW, Schlag PM, Stein U. RAGE mediates S100A4-induced cell motility via MAPK/ERK and hypoxia signaling and is a prognostic biomarker for human colorectal cancer metastasis. Oncotarget 2014;30:3220-3.

55. Siddique HR, Adhami VM, Parray A, Johnson JJ, Sidiqui IA, Shekhani MT, Murtaza I, Ambartsumian N, Konety BR, Mukhtar H, Saleem M. The S100A4 oncoprotein promotes prostate tumorigenesis in a transgenic mouse model: regulating NFKB through the RAGE receptor. Genes Cancer 2013;4:224-34.

56. Haase-Kohn C, Wolf S, Herwig N, Mosch B, Pietzsch J. Metastatic potential of B16-F10 melanoma cells is enhanced by extracellular S100A4 derived from RAW264.7 macrophages. Biochem Biophys Res Commun 2014;446:143-8.

57. Gibadulinova A, Tothova V, Pastorek J, Pastorekova S. Transcriptional regulation and functional implication of S100P in cancer. Amino Acids 2011;41:885-92.

58. Arumugam T, Simeone DM, Schmidt AM, Logsdon CD. S100P stimulates cell proliferation and survival via receptor for activated glycation end products (RAGE). J Biol Chem 2004;279:5059-65.

59. Arumugam T, Ramachandran V, Gomez SB, Schmidt AM, Logsdon CD. S100P-derived RAGE antagonistic peptide reduces tumor growth and metastasis. Clin Cancer Res 2012;18: 4356-64.

60. Onyeagucha BC, Mercado-Pimentel ME, Hutchison J, Flemington EK, Nelson MA. S100P/RAGE signaling regulates microRNA-155 expression via AP-1 activation in colon cancer. Exp Cell Res 2013;319:208190.

61. Ji YF, Huang $H$, Jiang F. S100 family signaling network and related proteins in pancreatic cancer. Int J Mol Med 2014;33:769-76.

62. Shubbar E, Vegfors J, Carlstrom M, Petersson S, Enerback C. Psoriasin (S100A7) increases the expression of ROS and VEGF and acts through RAGE to promote endothelial cell proliferation. Breast Cancer Res Treat 2012;134:71-80.

63. Petersson S, Shubbar E, Yhr M, Kovacs A, Enerback C. Loss of ICAM-1 signaling induces psoriasin (S100A7) and MUC1 in mammary epithelial cells. Breast Cancer Res Treat 2011;125:13-25.

64. Nasser NW, Qamri Z, Deol YS, Ravi J, Powell CA, Trikha P, Schwendener RA, Bai XF, Shilo K, Zou X, Leone G, Wolf R, Yuspa SH, Ganju RK. S100A7 enhances mammary tumorigenesis through upregulation of inflammatory pathways. Cancer Res 2012;72:604-15.

65. Yin C, Li H, Zhang B, Liu Y. RAGE-binding S100A8/A9 promotes the migration and invasion of human breast cancer cells through actin polymerization and epithelial-mesenchymal transition. Breast Cancer Res Treat 2013;142:297-309.

66. Hermani A, Hess J, De Servi B, Medunjanin S, Grobholz R, Trojan L, Angel P, Mayer D. Calcium-binding proteins S100A8 and S100A9 as novel diagnostic markers in human prostate cancer. Clin Cancer Res 2006; 11:5146-52

67. Hibino T, Sakaguchi M Miyamoto S, Yamamoto M, Motoyama A, Hosoi J, Shimokata T, Ito T, Tsuboi R, Huh NH.et al.: S100A9 is a nove ligand of EMMPRIN that promotes melanoma metastasis. Cancer Res 2013;73:172-83.

68. Yang M, Zeng P, Kang R, Yu Y, Yang L, Tang D, Cao L. S100A8 contributes to drug resistance by promoting authophagy in leukemia cells. PLoS One 2014;9:e97242,doi: 10.1371/journal.pone.0097242.

69. Wang H, Zhang L, Zhang IY, Chen X, Da Fonseca A, Wu S, Ren H, Badie S, Sadeghi S, Ouyang M, Warden CD, Badie B. S100B promotes glioma growth through chemoattraction of myeloid-derived macrophages. Clin Cancer Res 2013;19:3764-75.

70. Leclerc E, Heizmann CW, Vetter SW. RAGE and S100 protein transcription levels are highly variable in human melanoma tumors and cells. Gen Physiol Biophys 2009;28:F65-F75. 
71. Eckel-Passow JE, Serie DJ, Bot BM, Joseph RW, Hart SN, Cheville JC, Parker AS. Somatic expression of ENRAGE is associated with obesity status among patients with clear cell renal cell carcinoma. Carcinogenesis 2014;35:822-27.

72. Ishibashi Y, Yamagishi S, Matsui T, Ohta K, Tanoue R, Takeuchi M, Ueda S, Nakamura K, Okuda S. Pravastatin inhibits advanced glycation end products (AGEs)-induced proximal tubular cell apoptosis and injury by reducing receptor for AGEs (RAGE) level. Metabolism 2012;61:1067-72.

73. Matsui T, Yamagishi S, Takeuchi M, Ueda S, Fukami K, Okuda S. Irbesartan inhibits advanced glycation end product (AGE)-induced proximal tubular cell injury in vitro by suppressing receptor for AGEs (RAGE) expression. Pharmacol Res 2010;61:34-9.

74. Yamagishi S, Nakamura K, Matsui T. Regulation of advanced glycation end product (AGE)-receptor (RAGE) system by PPAR-gamma agonists and its implication in cardiovascular disease. Pharmaco Res 2009;60:174-8.

75. He X, Esteva FJ, Ensor J, Hortobagyi GN, Lee MH, Yeung SC. Metformin and thiazolidinediones are associated with improved breast cancerspecific survival of diabetic women with HER2+ breast cancer. Ann Oncol 2012;23:1771-80.

76. Arumugam T, Ramachandran V, Sun D, Peng Z, Pal A, Maxwell DS, Bornmann WG, Logsdon CD. Designing and developing S100P in- hibitor 5-methyl cromolyn for pancreatic cancer therapy. Mol Cancer Ther 2013;12:654-62.

77. Rao NV, Argyle B, Xu X, Reynolds PR, Walenga JM, Prechel M, Prestwich GD, MacArthur RB, Walters BB, Hoidal JR, Kennedy TP. Low anticoagulant heparin targets multiple sites of inflammation, suppresses heparin-induced thrombocytopenia, and inhibits interaction of RAGE with its ligands. Am J Physiol Cell Physiol 2010;299:C97-C110.

78. Mizumoto S, Takahashi J, Sugahara K. Receptor for advanced glycation end products (RAGE) functions as receptor for specific sulfated glycosaminoglycans, and anti-RAGE antibody or sulfated glycosaminoglycans delivered in vivo inhibit pulmonary metastasis of tumor cells. J Biol Chem 2012;287:18985-94.

79. Yamagishi S, Matsui T. Soluble form of a receptor for advanced glycation endproducts as a biomarker. Front Biosci 2010;2:1184-95.

80. Nogueira-Machado JA, de Oliveira Volpe CM. HMGB-1 as a target for inflammation controlling. Recent Pat Endocr Metab Immune Drug Discov 2012;6:201-09.

81. Radia AM, Yaser AM, Ma X, Zhang J, Yang C, Dong Q, Rong P, Ye B, Liu $S$, Wang W. Specific siRNA targeting receptor for advanced glycation end products (RAGE) decreases proliferation in human breast cancer cell lines. Int J Mol Sci 2013;14:7959-78. 